\title{
PAISAGISMO E MONITORAMENTO ECOLÓGICO EM CONDOMÍNIO INSERIDO EM FRAGMENTO FLORESTAL DO DOMÍNIO TROPICAL ATLÂNTICO
}

\author{
Josimar Ribeiro de Almeida \\ jralmeida@usp.br \\ Observatório Urbano/UERJ/UN-Habitat \\ Manoel Gonçalves Rodrigues \\ manoel.rodrigues@terra.com.br \\ Observatório Urbano/UERJ/UN-Habitat \\ Solange Mathias de Almeida \\ solange.mathias@gmail.com \\ Núcleo de Análise de Sistemas Ambientais/UFRJ \\ Roberto Ricardo Rachid Saab Barbosa Cunha \\ rachidsaab@gmail.com \\ Observatório Urbano/UERJ/UN-Habitat
}

\begin{abstract}
RESUMO
Um projeto paisagístico, de caráter ecológico, deve ser abordado levando-se em conta fatores não só de ordem estética, mas, sobretudo, adaptando-o aos fatores ambientais determinantes, visando à reconstituição, conservação e preservação da fitofisionomia originais. Quanto à área de implantação deste tipo de projeto se localiza numa zona de Mata Atlântica, cuja manutenção é vital, há que ter-se uma enorme responsabilidade para com a natureza. Sua importância se faz sentir no equilíbrio hídrico de uma região; nas condições climáticas; na manutenção da vida animal; na preservação de espécies vegetais de enorme riqueza genética; na proteção dos solos contra deslizamentos, ravinamentos e voçorocas. O terreno em questão envolve uma área denominada "Quinta do Paraíso", antiga fazenda, onde grandes áreas foram desmatadas. Algumas ilhas de vegetação da mata original, porém, foram preservadas. Existe ainda no local vestígio de Mata Atlântica Primária e Secundária. O local caracterizase por acentuada movimentação topográfica, visto que faz parte do Complexo da Serra dos Órgãos, na região N-NO e esta é sua característica mais marcante, seguindo as características da Serra do Mar. A altitude varia entre a cota 920 e a cota 1160, formando elevações, por vezes abruptas, com afloramentos rochosos, ou pequenos morros entre os quais se delineiam pequenos espaços mais planos, pequenas planícies aluviais, que facilitam a adequação do terreno ao empreendimento pretendido.
\end{abstract}

Palavras-Chaves: Paisagismo ecológico - Monitoramento Fragmento florestal - Tropical atlântico 


\begin{abstract}
A landscape architecture project with a an ecological characteristic should be approached taking into account not only factors of aesthetic order but, above all, adapting itself to decisive environmental factors, seeking the rebuilding, conservation and preservation of the original phytofysionomy. That is actually men's responsibility in contributing to restore what he has actually degraded - the life quality - and beyond making it pleasant to our eyes, making it a remarkably responsible project from the ecological point of view. As for the implantation area of this project type, it is located in an Atlantic forest area, whose maintenance is vital, there should have an enormous responsibility towards nature. Its importance lies on the hydric area balance; climatic conditions; animal life maintenance; vegetable species preservation of enormous genetic wealth; protection of the soils against sliding, ravinamentos and voçorocas that cause so many problems during the great summer thunderstorms. Finally, uncountable important factors for life in general and for the well being of human beings. The land in question involves an area denominated "Quinta do Paraíso", an old farm where great areas were deforested. Some vegetation islands of the original forest, however, were preserved. It still exist some traces of the Primary and Secondary Atlantic forest. The place is characterized by having accentuated topographical movement, because it is part of the Complexo da Serra dos Orgãos, in the area N-NO and that is its more outstanding characteristic, following the Serra do Mar characteristics. The altitude varies between 920 quota and 1160 quota, forming elevations, sometimes abrupt with rocky blooming or small hills among which small spaces are outlined, small alluvial plains are delineated, which facilitate the land adaptation to the intended enterprise.
\end{abstract}

Key-Words: Ecological Landscape, Monitorization, Forest Fragment, Atlantic Tropical

\title{
INTRODUÇÃO
}

Um projeto paisagístico, de caráter ecológico, deve ser abordado levando-se em conta fatores não só de ordem estética, mas, sobretudo, adaptando-o aos fatores ambientais determinantes, visando a reconstituição, conservação e preservação da fitofisionomia originais. Isto é na verdade, a responsabilidade do homem em contribuir para restaurar o que ele mesmo degradou - a qualidade de vida - e torná-lo além de agradável aos olhos, um projeto marcadamente responsável do ponto de vista ecológico.

Sendo o presente objeto de estudo um projeto destinado à implantação de um loteamento residencial, com características de condomínio fechado, é de fundamental importância a "qualidade de vida" de seus moradores, devendo ter em vista conceitos tais como: beleza cênica, espaços de recreação e lazer, sem, no entanto, esquecer os ecológicos e ambientais, visando integrar o projeto ao meio físico sem ferir a sua fisionomia. 
Quanto à área de implantação deste tipo de projeto se localiza numa zona de Mata Atlântica, cuja manutenção é vital, há que ter-se uma enorme responsabilidade para com a natureza. Sua importância se faz sentir no equilíbrio hídrico de uma região; nas condições climáticas; na manutenção da vida animal; na preservação de espécies vegetais de enorme riqueza genética; na proteção dos solos contra deslizamentos, ravinamentos e voçorocas que tantos problemas causam quando das grandes trovoadas de verão. Enfim, uma infinidade de fatores de suma importância para a vida de uma forma geral e o bem estar do próprio ser humano.

Portanto, deverá fazer-se um estudo profundo e honesto das condições locais: solos e suas composições físico-químicas $(\mathrm{pH}$, granulometria, $\mathrm{N}, \mathrm{P}, \mathrm{K})$; da biodiversidade original, para que se possa determinar as espécies destinadas ao enriquecimento dos solos e que se ajudem ao sistema ecofisiológico local; o tipo de ocupação a que se destina, enfim, determinar as necessidades básicas locais e sanálas. Só então, deve-se dar início à implantação do projeto, procurando adequá-lo e integrá-lo às características físicas e ecológicas originais e também às exigências econômico-sociais, prevendo uma possível exploração dos recursos naturais, tendo em vista o binômio desenvolvimento $x$ conservação. Os cenários serão compostos levando-se em consideração a evolução dos processos naturais e a interrelação com o meio social.

\section{MATERIAL E MÉTODOS}

\section{Características fisiográficas da unidade ambiental}

A Serra dos Órgãos - complexo formado essencialmente por gnaisses do complexo arqueano brasileiro - no reverso da Serra do Mar caracteriza-se por acentuados desníveis, com grandes elevações separadas por depressões. A rede de drenagem atuando sobre as rochas de menor resistência - os sedimentos - formou pequenos vales intermorros e assim escavando e carreando materiais, foi, passo a passo, redesenhando novos cenários paisagísticos de maneira lenta e natural. Porém, esta ação foi enormemente intensificada pela ação antrópica, com o mau uso que se 
fez da terra para adaptá-la aos seus interesses agrícolas, desmatamento, queimadas, pecuários, pisoteio, trilhas, obras rodoviárias mal planejadas do ponto de vista ambiental e mesmo a falta de uma legislação mais atuante a proteção do meio ambiente. Tudo isso em muito contribuiu para a aceleração deste processo degradador que passou a ser também destrutivo, devastando os antigos cenários naturais.

O terreno em questão envolve uma área denominada "Quinta do Paraíso", antiga fazenda, onde grandes áreas foram desmatadas. Algumas ilhas de vegetação da mata original, porém, foram preservadas. Existe ainda no local vestígio de Mata Atlântica Primária e Secundária.

Podem ser observadas várias aéreas de degradação ambiental e a devastação causada pela ação antrópica através do tempo: empobrecimento do solo, ravinamento, deslizamento etc., como conseqüência de desmatamento e inadequada utilização dos solos, seja com monoculturas passadas, como a cafeeira, muito explorada desde meados do século XIX, ou como campos de pastagem para a pecuária na região, por volta da década de 30 já no século XX.

O local caracteriza-se por acentuada movimentação topográfica, visto que faz parte do Complexo da Serra dos Órgãos, na região N-NO e esta é sua característica mais marcante, seguindo as características da Serra do Mar. A altitude varia entre a cota 920 e a cota 1160, formando elevações, por vezes abruptas, com afloramentos rochosos, ou pequenos morros entre os quais se delineiam pequenos espaços mais planos, pequenas planícies aluviais, que facilitam a adequação do terreno ao empreendimento pretendido.

A linha perimetral é delineada partindo-se, à direita, da cota 920, na Estrada da Prata, e contornando a área denominada "Quinta do Paraíso", fazendo divisa com os lotes nos 15, 16 e 17 até encontrar de novo a estrada da Prata, acompanhando-a até fechar o contorno do empreendimento, que compreende: áreas desmatadas em processo de degradação; áreas de floresta remanescente da mata nativa; algumas construções; 3 fontes de água mineral, e uma canaleta de drenagem de águas.

Localiza-se em Teresópolis às margens da Estrada da Prata, em uma área de expansão natural, imediata, da cidade. O acesso fácil e o fato de fazer parte de uma Revista Internacional de Ciências · v.3 - n.1 · jan./jun. 2013 
área de ocupação rarefeita e, principalmente, considerada de baixa renda - o que certamente torna o valor da terra mais baixo - determinam e facilitam esta característica. Estas condições, entretanto, facilitam também, a adequação do lugar ao tipo de empreendimento, ora pretendido. A "Quinta do Paraíso" possui uma área total de 498.750,25 m2, dos quais $319.200,00 \mathrm{~m} 2$ serão loteados, num total de 351 lotes. As áreas municipais somam 28.264,55 m2, assim distribuídos: parques: 11.188,30 m2; bosques/escolas: 11.159,50 m2; proteção de minas (fontes de água mineral): 2.249,50 m2; jardins: $3.667,25 \mathrm{~m} 2$ e arruamento: $55.470,00 \mathrm{~m} 2$, ou seja, $11,12 \%$ da área. Somam um total de $121.319,00 \mathrm{~m} 2$ as áreas verdes (reservas e áreas municipais).

\section{Interações e descrição da ecodinâmica}

As montanhas, cobertas por florestas, atuam como condensadores de umidade e têm relevante importância na manutenção do clima. A Mata Atlântica é a denominação genérica da fitofisionomia local, da qual faz parte a Floresta Tropical Úmida, que se estende pelas encostas e morros do local. A pluviosidade tem enorme importância na manutenção e desenvolvimento deste tipo de floresta. Primeiro, pelo poder que a floresta tem de reter umidade, depois, porque a água que penetra no solo levando materiais nutritivos e agindo quimicamente sobre os minerais que o compõem, produz novos elementos necessários à composição dos solos que vão garantir a manutenção da cobertura vegetal.

A ação desta cobertura, que com seus diversos níveis de vegetação (estrutura em degraus) - árvores, vegetação arbórea arbustiva e serapilheira - vão amortecendo o impacto da chuva, atuando diretamente sobre o sistema de escoamento das águas, filtrando e proporcionando o escoamento gradativo em direção aos reservatórios de água subterrâneos, atingindo, a partir daí, os córregos ou formando fontes, por vezes de águas minerais (existem 3 no local). Além das folhas que captam e sintetizam, através da fotossíntese, a serapilheira - emaranhado de raízes, musgos, fungos, matéria orgânica em decomposição e microorganismos - desempenha papel essencial na reciclagem dos elementos nutritivos. As águas retidas nesse tapete vão agir diretamente na natureza físico-química dos materiais inertes e na decomposição da matéria orgânica proveniente da decomposição das folhas e galhos e levar os 
nutrientes dissolvidos reciclados pelos microorganismos, diretamente para as raízes das plantas, suprindo suas necessidades básicas de substancias nutritivas. Em conclusão, é necessário compreender que os mecanismos de conservação fazem parte da estrutura orgânica viva da floresta e que para se conseguir um desenvolvimento e manutenção satisfatória do florestamento é necessário, primeiramente, repor e manter esses mecanismos.

As árvores das florestas primárias crescem lentamente. Suas sementes, que não são muitas, precisam de sombra e umidade para germinar, essas árvores não podem fixar-se novamente em terrenos devastados. Para se recompor os mecanismos de conservação, é necessário o elemento "pioneiro" na colonização do solo. São grupos de arbustos heliotrópicos, vegetação rasteira e árvores de pequeno porte e vida curta, que aparecem na floresta após perturbações impactantes. As variedades dessas espécies de arbustos e árvores pequenas têm a propriedade de lançar raízes rapidamente e ocupar as camadas superiores do terreno. A importância dessas espécies "pioneiras" é que elas criam as condições de umidade e sombra necessária à reprodução das árvores da floresta primária. Além do que, têm ciclo de vida curto, pois se alimentam, umas, das substâncias nutritivas das outras, transformando-se em matéria orgânica que será novamente reciclada, estabelecendo, assim o ciclo vital.

\section{Fitofisionomia da Floresta Pluvial Úmida}

A contínua ação antrópica local modificou, não só a topografia, como também, a fitofisionomia primária, não restando muito da vegetação original (Floresta Ombrófila densa). Os solos da região são argilosos, genericamente classificados como latossolos, litossolos e hidromórficos. Estes tipos de solos são pobres e sua estabilidade estrutural concorre diretamente no escoamento das águas, podendo facilitar desmoronamentos ou ravinamentos.

O reflorestamento e o paisagismo a ser implantados devem ter orientação a impedir uma degradação maior e, estabelecer critérios, tais como, evolução tendendo para a estabilidade morfogênica, através de processos de correção destinados a neutralizar os efeitos das chuvas torrenciais; recuperação e conservação da biodiversidade, além do efeito cênico. Estes tipos de solo, depois de limpos de sua 
vegetação original, cuja biomassa os nutre e thes confere uma revigorante camada de húmus, com a sucessiva lixiviação pelas águas, vão perdendo seu poder de regeneração, tendo que ser, para tanto, tratados $\mathrm{cm}$ os nutrientes que se perderam.

A vegetação terá que ser criteriosamente escolhida para que, por suas propriedades, auxilie neste tipo de recuperação e também propicie a espécie de mais difícil poder de colonização, condições para se desenvolverem.

O reflorestamento e a revegetação paisagística deverão ser elaborados a partir de uma área de tamponamento, que segue a linha perimetral do terreno e se inicia na Estrada do Prata, à direita do empreendimento, com uma área reservada ao IBF, fazendo uma zona de interface com a Colônia da Prata até a cota 1070, onde se alarga, continuando depois com uma área de Reserva Florestal até à cota 1140, na divisa com o lote no 16 reiniciando depois, à esquerda, até atingir a área destinada à escola. Aqui se interrompe o cordão verde com a intrusão de um grande lote às margens da Estrada da Prata, reiniciando-se na área non aedificandi de $15 \mathrm{~m}$ de largura, ao longo da referida estrada, passa pelo acesso ao loteamento, terminando numa área destinada a Parque Municipal.

O cordão de tamponamento vegetal envolve, praticamente, todo 0 empreendimento. Isto criará condições climáticas agradáveis, além d minimizar a poluição sonora e visual.

\section{Caracterização Climática e recomposição Florestal}

O clima é tropical de inverno, seco e ameno. A Serra do Mar propicia obstáculos aos ventos marítimos as elevações protegem as várzeas da neblina. $O$ índice pluviométrico é alto, porém, à medida que a altitude aumenta, o índice tende a cair. A estação das chuvas é no verão, não tendo, entretanto, nenhum período completamente seco, pois, no outono/inverno, que seria o período de estiagem, ocorrem as precipitações polares de climas pseudo-equatoriais da costa oriental.

Para uma completa e eficaz regeneração da floresta deve ser feita uma reposição total ou parcial das espécies, através de semeadura ou por processo vegetativo, estacas, etc. Isto significa que o homem agindo em conjunto com a 
natureza pode perpetuar espécies e preservar a diversidades genéticas, tanto da flora, quanto da fauna, pois nas condições adequadas de habitat, animais raros ou em vias de extinção, podem voltar a se reproduzir e de novo colonizar o espaço que já foi seu.

A propagação das espécies poderá ser feita de várias maneiras, pelo vento, pássaros, água, insetos e mamíferos silvestres e sua germinação vai depender das condições do substrato.

As espécies selecionadas para plantio serão as regionais representativas da flora de Mata Atlântica. As mudas de árvores terão um espaçamento de $4 \mathrm{~m} \times 4 \mathrm{~m}$ e serão selecionadas entre as seguintes: Chorisia crispiflora (Paineira) - Floresce de Fevereiro a Maio, flores em vários tons de rosa. Porte alto, textura leve, copa volumosa, bem espalhada. Própria como árvore isolada ou em combinações. Propaga-se por sementes; Hymennaea altíssima (Jatobá) - Copa em forma de guardachuva, tronco ereto. Própria para aléias ou como planta isolada. Produz frutos comestíveis e propaga-se por sementes; Tecoma haptaphylla (Ipê roxo) - crescimento lento, floresce em Setembro, suas flores possuem diversos tons. Perde totalmente as folhas no período de floração; Tecoma chrysitricha (Ipê amarelo) - Floresce de Julho a Setembro, flores amarelas, folhas caducas. Tem porte pequeno e ereto, textura leve, pouco ramificada; Mimosa caesalpinifolia (Sabiá) - Espécie "pioneira" de solos rústicos, com baixos teores de elementos nutritivos, porte médio, textura leve. Suas flores são brancas; Lafoencia glyptocarpa (Merindiba) - Espécie nativa da flora carioca é caracterizada por sua elevada rusticidade, crescimento rápido e floração de Agosto a Setembro. As flores são brancas e grandes; o seu porte é médio, muito ramificado de textura leve. Pode ser usada em blocos ou combinadas com outras árvores de textura pesada. Propaga-se por sementes; Cariniana legalis (Jequitibá) - Grande porte (30/40m de altura). Suas flores são brancas e pequenas; Cariniana excelsa (Jequitibá); Caesalpinae peltophoroides (Sibipiruna) - Porte médio, crescimento lento, floresce Floresce duas vezes por ano, flores amarelas em cachos. Copa em forma de guardachuva, textura leve, com ramificação bem distribuída. Altamente decorativa em grupos ou isoladas, servindo para sombra e aléias, propaga-se por sementes; Fícus catapaefolia; Fícus clusiaefolia; Fícus enormis (Mata pau) - Espécies de grande porte 
(30m), copa arredondada, muito ramificada, textura pesada. Propaga-se por estaca herbácea com folhas; Arecastrun romanzoffianum (Jerivá) - Palmeira com estipe ereto, alto e liso. É geralmente, transplantada quando jovem de pequeno ou médio tamanho, dos viveiros para área de cultivo; Euterpe edulis (Palmito doce) - Estipe liso, ereto e de cor cinza. Seu transplante das matas é difícil sendo necessário obterem-se as mudas em viveiros especializados; Tibouchina granulosa - Floresce de Fevereiro a Abril. Suas flores são róseas, muito vistosas, porte médio, textura pesada, copa semiglobulosa muito ramificada. Propaga-se por sementes; Cássia ssp - Floresce de Fevereiro a Abril. Suas flores são amarelas, porte médio, textura leve. Propaga-se por sementes; Cássia macranthera (Fedegoso) - Porte médio, flores amarelas em cacho. Floresce em Agosto; Vochysisia laurifólia - (Murici); Swartzia langsdorfii - (Pacovamacaco) e Ingá affonsea - (Ingá).

Quaresmeiras e Embaúbas, estão também entre os representantes de sua vegetação arbórea, além de Orquídeas, Bromélias, Begônias, Marantas, Fetos, Esponjas e grande variedade de outras leguminosas, aromáticas, decorativas e medicinais.

\section{Referencial metodológico e parâmetros para o programa de biomonitoramento.}

O monitoramento da fauna e flora terá como base a dinâmica dos processos ecossistêmicos. Portanto o conjunto de parâmetros monitorados indicará o estado de residência biótica frente às modificações ambientais. A metodologia de monitoramento adotada aborda variáveis físicas fundamentais no ecossistema (deslocamento de matéria e balanço energético) assim como variáveis bióticas (deslocamento de matéria, fenologia, etiologia e auto-ecologia).

O modelado ambiental local caracteriza-se por um conjunto de feições, que de modo geral para efeito de monitoramento, podem ser categorizados em: fragmento florestal, segmentos fitosucessionais e áreas de constructos/obras antrópicas.

Os fragmentos florestais compreendem, na ótica do empreendimento, as reservas florestais que ladeiam a propriedade. Esses trechos se estendem numa configuração leptocúrtica do topo até a rampa coluvial. As estações de monitoramento devem estar distribuídas de modo que uma delas esteja no core do fragmento florestal Revista Internacional de Ciências · v.3 - n.1 · jan./jun. 2013 
e as outras nas bordas. Essas por sua vez deverão ser em número que abranja as linhas perimetrais e os vetores de tensão ecotonal, evolução do modelado (por influência hidrológica), os processos periculares e a susceptibilidade a fenômenos de amplificação. Um total de 13 (treze) estações atenderá os objetivos do monitoramento, com pontos fixos nas linhas de dinâmica ambiental já indicada e com mobilidade para escaneamento transectal.

Os segmentos fitosucessionais a serem mantidos e inclusive recompostos, serão atendidos pelas 12 estações das bordas dos fragmentos florestais. Quanto as áreas de constructos/obras antrópicas, deverão ser tratada pelas mesmas estações de monitoramento; no entanto com preocupações dirigidas à outros parâmetros. Destacando-se a correlação entre o programa de monitoramento e o programa de mitigação. Neste caso importam fundamentalmente questões relativas a terraplanagem, ruídos, emanações gasosas do escape de máquinas, relocação de recursos hídricos, comportamento do contingente operário quanto a fauna-flora, destinação de águas residuárias e outros descartes do acampamento de obras. Além de outros aspectos menos destacáveis, passíveis de efeito sinérgico.

Os processos de natureza pelicular serão avaliados pelo movimento do regolito, através da velocidade de rastejamento. A medida de distancia de acamação à jusante indicará o estado de reptação ("creep") da linha de borda dos fragmentos florestais. Este indicador juntamente com os rastros de vetores de solifluxão vão permitir um monitoramento da saída de matéria no ecótone florestal.

Os processos morfogenéticos fundamentalmente pluviais serão monitorados pelos vetores de escoamento pluvial. As observações deverão ser feitas no interflúvio através do movimento vertical da água superficial (profundidade de cavitação/saltitação e densidade de ranhuras no terreno). No declive com infiltração, o balisador de monitoramento será a eluviação mecânica e na rampa de colúvio, formação de cones de dejeção e a adução de linhas de transportes. As resultantes do parâmetro morfogenéticos irão compor a equação de deslocamento da matéria, juntamente o balanço morfogenético da serrapilheira. 
O balanço morfogenético e dinâmica de serrapilheira resultam da ação combinada dos componentes verticais e paralelos. O balanço será considerado em dois pontos nos fragmentos florestais: nas linhas de montante e nas linhas de jusante. No primeiro caso utilizar-se-á a equação $\mathrm{BM}=\mathrm{V}-\mathrm{P}$, onde $\mathrm{BM}=$ Balanço morfogenético, $V=$ Componente vertical (input de matéria), $p=$ componente paralela (output de matéria). No segundo caso a equação será $B M=(V+d)-P$, onde $d=$ Detritos de montante. Apesar de ser uma medida paramétrica indireta das atividades de flora, o monitoramento da serrapilheira é importante componente do balanço de massa (no caso biomassa) que juntamente com os parâmetros morfogenéticos do modelado compõem a equação de deslocamento de matéria.

Entre as variáveis físicas fundamentais do ecossistema, o balanço de massa será monitorado através dos parâmetros morfogenéticos do modelado e da dinâmica de serrapilheira enquanto o balanço energético será monitorado através da estimativa de balanço médio diário mensal de radiação da superfície, déficit de saturação e calculo de evapotranspiração diária e mensal.

O balanço da radiação será calculado a partir da equação de Angstrom com constantes de Glover \& Mcllosh. Serão efetuados cálculos da radiação solar refletida $(Q R)$, radiação solar absorvida $(Q O C)$, radiação de superfície $(Q S)$, emissão efetiva terrestre (QOL) e o balanço de radiação $(Q)$. O resultado final dado em cal/cm2/dia será oriundo da equação final $Q=Q O C+Q O L$, I.E. a soma dos balanços de radiação de ondas curtas e ondas longas. O balanço da fisiologia ambiental hídrica será efetuado através da medida do déficit de saturação $(\mathrm{mm} . \mathrm{Hg})$ pelo nomograma de BENNET \& HUMPRHEYS. O cálculo da evapotranspiração potencial diária será feito pelo método de Penmanbavel, enquanto a evapotranspiração potencial mensal será calculada pelo método de Thornthwaite.

Os balanços dos parâmetros-chaves da estrutura funcional do ecossistema permitirão monitorar a partir de $\mathrm{T}$ (zero) até $\mathrm{T}(\mathrm{ene})$ o nível de mudança na resistência estrutural do sistema. Esses dados conjugados as variações de estado, daqueles de natureza biótica, permitirão um acompanhamento monitoral sistêmico das ações impactantes e conseqüentes reações biossistêmicas do ambiente em pauta. 
No monitoramento dos parâmetros fitosociológicos será utilizado transecto de banda nas amostragens de interface ecotonal e um quadract na área core do fragmento florestal. O registro da estrutura da vegetação será feito pelo método de Dansereau, enquanto os aspecto os aspectos sinecológicos serão tratados pelo método de BraunBlanquet, com inserções de outras metodologias especificada em cada caso.

Os parâmetros analisado serão: cobertura, espaço, estimativa total, sociabilidade (método de Willdenov), freqüência, estratificação (métodos de Kerner \& Ragnar e HultSernander), graus de vitalidade, fenologia (método de Diels \& Scharfetter), graus de presença (método de Brockmann-Jerosch), fidelidade e expressão da construtividade (método de Pavillard).

Onde os custos da manutenção antitérmica impostos pelo ambiente físico são reduzidos, I.E. quando a razão $R / B$ (respiração/biomassa) é baixa, pode haver destinação à diversidade maior quantidade de energia da comunidade. Conseqüentemente, as comunidades em ambientes estáveis, como seja a floresta tropical úmida tem diversidades de espécies mais altas do que as comunidades submetidas a perturbações por ação humana. A estabilidade do ecossistema, bem como a diversidade biológica, são afetadas pelas oscilações externas no habitat físico.

A diversidade será tratada no monitoramento através de busca ativa em corredores transectais. O esforço de observação envolverá conhecimento profissional prévio, traçado pré-determinado e horários alvos. Serão considerados na ornitofauna, os artefatos fisiológicos (vezes, penas, ovos), os artefatos etológicos (ninho, captura de material construtivo) e atividades consideradas comportamentais (cantos, imagens). Para mastofauna serão considerados: pelotas e fezes, pegadas, vocalizações, imagens e indicativos de habitats, como caça, aninhamento e dessedentação. Na herpetofauna consideraremos localização de indivíduos, imagens, vocalizações e indicativos de microhabitats.

As principais vias de reciclagem de nutrientes estarão sendo indiretamente monitoradas. A via de reciclagem I excreção animal primaria, através de fezes de herbívoros e carnívoros. A via de reciclagem II - Decomposição microbiana de detritos, 
através do monitoramento de serrapilheira, isto incluiu a excreção de comedores de detritos, carnívoros da liteira, além de comedores de fungos e bactérias.

\section{CONCLUSÕES}

Em que pese às dificuldades inerentes a qualquer monitoramento, tanto no nível operacional quanto de referencial teórico, o presente caso apresenta dificuldades adicionais.

Primeiro porque se trata de uma área sem monitoramentos anteriores, semelhantes ao proposto. Isto significa que o T(zero) do monitoramento deverá ocorrer antes do início de qualquer obra.

O segundo aspecto da dificuldade impar deste monitoramento refere-se a sua abrangência e complexidade. Optar-se por uma linha de captura-recaptura de segmentos faunísticos, seria bastante trabalhosa, onerosa e certamente com um custo de estresse adicional à fauna ou então, opta-se, conforme indicado neste programa, por uma linha de indicadores ecológicos de função/processo e estrutura ecossistêmicas. No primeiro caso dificulta-se a obtenção dos dados e facilita-se em termos a análise. Na segunda opção, inverte-se a problemática. Em que pese as dificuldades operacionais de monitoramento são muito boas. Os parâmetros indicados abordam função-processo energéticos, ciclagem de matéria, estrutura de composição taxocenótica, além de táticas bionomicas e ecológicas.

\section{REFERERÊNCIAS BIBLIOGRÁFICAS}

Dons, A. (1986) The effect of large-scale afforestation on Tarawera river flows. Journal of Hidrology, 25 (2), 61-73.

Fujieda, M.; Tetsuya, K; Cicco, V. e Calvarcho, J. L. de. (1997) Hydrological processes at two subtropical forest catchments: the Serra do Mar, São Paulo, Brazil. Journal of Hidrology 196 (1997) 26-46. 
Scott, D. F. e Lesch, W. (1997) Streamflow responses to afforestation with Eucaliptus grandis and Pinus patula and to felling in the Mokubulaan experimental catchments, South Africa. Journal of Hidrology, 199(1997) 360-377. 